\title{
Topical immunotherapy for pseudomonas keratitis in rabbits: use of antilipopolysaccharide plasma
}

\author{
N. H. WELSH, ${ }^{1}$ A. J. RAUCH, ${ }^{2}$ AND S. L. GAFFIN ${ }^{2}$ \\ From the 'Departments of Ophthalmology and ${ }^{2}$ Physiology, University of Natal, Medical School, \\ Durban, South Africa
}

SUMmARY Pseudomonas keratitis is currently treated with antibiotics with a variable success rate. Part of the morbidity caused by pseudomonas is due to the action of lipopolysaccharide (LPS) present on the surface membrane of the bacteria. Specific IgG present in equine anti-LPS hyperimmune plasma has been found to bind to the LPS from a range of Gram-negative bacteria, including pseudomonas, and by activating complement it destroys these bacteria. Anti-LPS plasma was therefore used as a therapeutic agent in experimentally induced pseudomonas keratitis in rabbits. Thirteen out of $15(86.7 \%)$ anti-LPS treated eyes improved, whereas four out of 17 $(23.5 \%)$ saline treated control eyes improved $\left(\chi^{2}=12.76 \mathrm{p}<0.001\right)$. No ill effects were noted when anti-LPS was administered to healthy rabbit or baboon eyes. Anti-LPS thus was protective in pseudomonas keratitis, and clinical trials appear to be warranted.

Pseudomonas aeruginosa is responsible for severe keratitis that may progress to panophthalmitis. It is particularly disastrous when it occurs as a postoperative complication of invasive surgery-for example, penetrating keratoplasty. Current therapy is based on antibiotics with antipseudomonal activity, such as gentamicin and tobramycin. ' High systemic doses are required to obtain adequate intraocular drug levels. The use of these agents is associated with a high incidence of side effects such as ototoxicity and nephrotoxicity. ${ }^{2}$

The pathophysiology of pseudomonas infections involves a number of components and products of the bacterial cell. ${ }^{3}$ Enzymes are produced which have a destructive effect on the host cell-for example, proteases and elastases. The lipopolysaccharide (LPS, endotoxin) component of the cell wall has also been implicated in the disease. ${ }^{45}$ This has been shown to be the cause of non-infectious corneal ring formation, mediated by complement activation. ${ }^{67}$ Antibiotics exert a direct antibacterial effect only, and thus immunotherapy directed at other aspects of the condition has enjoyed increased attention. ${ }^{8}$

Gaffin and colleagues have developed an equine anti-LPS hyperimmune plasma containing specific

Correspondence to Professor N. H. Welsh, Department of Ophthalmology, University of Natal Medical School, PO Box 17039, 4013 Congella, South Africa.
IgG which binds to free LPS and also has bactericidal properties. ${ }^{910}$ This plasma has been used successfully to treat a variety of Gram-negative infections involving LPS in horses, dogs, cats, sheep, and rats. " 12 The diversity and cross-reactivity of the antibodies in the preparation enable it to kill a wide range of Gram-negative bacteria, including pseudomonas, klebsiella, Escherichia coli, proteus, shigella, and salmonella. Such serum or plasma has recently proved effective in the prophylaxis and therapy of endotoxaemia in the veterinary field, particularly the race horse industry of South Africa. ${ }^{12}$

This study has been conducted to determine whether anti-LPS hyperimmune equine plasma (antiLPS) would be effective in treating corneal pseudomonas infections. Anti-LPS was first tested against in-vitro cultures of Pseudomonas aeruginosa and found to be bactericidal. The serum was then found safe to use topically on normal rabbit eyes, as a lavage. The anti-LPS was then used therapeutically on experimentally induced pseudomonas keratitis in rabbits.

\section{Materials and methods}

An untyped culture of Pseudomonas aeruginosa was obtained from a microbiology department of a university hospital. It was cultured in nutrient broth for 
24 hours to a final concentration of $600-900$ million organisms $/ \mathrm{ml}$.

Anti-LPS was prepared from horses by plasmapheresis, suitably immunised (Atox Pharmaceutical Co., 14 Old Main Road, 3600 Gillitts, South Africa). The plasma contained $1500 \mu \mathrm{g} / \mathrm{ml}$ of LPS precipitable antibodies. These antibodies could bind to endotoxins prepared from Shigella flexneri, five strains of E. coli, five species of Salmonella, Klebsiella, Proteus, and Pseudomonas.

Rabbits of mixed, non-inbred, strain, weighing $2 \cdot 5$ $3.5 \mathrm{~kg}$ were used. All had normal corneas and anterior segments. The corneas were anaesthetised locally with 3 drops of oxybuprocaine $\mathrm{HC} 1$ prior to inoculation.

\section{METHOD OF INOCULATION}

Two methods were used to show that anti-LPS was effective in both moderate (group A) and severe infections (group B).

Group A. Both corneas of rabbits were prepared by making three deep vertical and horizontal incisions into the stroma, in a cross-hatch pattern, with a sterile 20 gauge needle, according to Furgiuele. ${ }^{13}$ The epithelium was removed in a $5 \times 5 \mathrm{~mm}$ area. Four drops of the bacterial inoculum were dropped on to the cornea and allowed to remain in contact with the cornea and inferior fornix for $\mathbf{3 0}$ seconds.

Group B. Rabbit eyes were infected with contaminated sutures. ${ }^{14}$ A virgin silk suture (8/0) was soaked for five minutes in a broth culture of pseudomonas. The suture was then passed through the corneal stroma. The ends were cut, and the sutures were allowed to remain in the cornea for two days. The lids were not sutured together.

After inoculation the animals were examined daily. The eyes were photographed at the beginning and end of treatment and the lesions were assessed on slit-lamp biomicroscopy. The severity of the infection present was graded according to the following criteria: (a) area of cornea involved; (b) depth of lesion; (c) degree of vascularisation.

Table 1 Method of scoring severity of experimental pseudomonas keratitis

\begin{tabular}{|c|c|c|c|c|c|}
\hline $\begin{array}{l}\% \text { Surface } \\
\text { of cornea } \\
\text { affected }\end{array}$ & $\begin{array}{c}\text { grade } \\
(a)\end{array}$ & $\begin{array}{l}\text { Density and } \\
\text { depth }\end{array}$ & $\begin{array}{c}\text { grade } \\
\text { (b) }\end{array}$ & $\begin{array}{l}\text { vascular- } \\
\text { isation }\end{array}$ & $\begin{array}{l}\text { grade } \\
\text { (c) }\end{array}$ \\
\hline 0 & (a) 0 & None & (b) 0 & None & (c) 0 \\
\hline $1-33$ & (a) 1 & Mild macula & (b) 1 & Mild & (c) 1 \\
\hline $34-66$ & (a) 2 & $\begin{array}{l}\text { Moderate } \\
\text { leucomatous }\end{array}$ & (b) 2 & Moderate & (c) 2 \\
\hline $67-100$ & (a) 3 & $\begin{array}{l}\text { Severe leuco- } \\
\text { matous } \\
\text { perforation }\end{array}$ & (b) 3 & Severe & (c) 3 \\
\hline
\end{tabular}

Maximum score totally all factors $a+b+c=9$.
This system was modified from that of previous workers. ${ }^{15}{ }^{16}$ Each grade varied from 0 to 3 points. Thus (a) 0 , indicated no infection, (a) 1 , up to $33 \%$ corneal area involved, (a) 2,33 to $66 \%$, (a) 3,66 to $100 \%$ affected. If the opacification was nebulous, the score was (b) 0 , if it was macula (b) 1 , if it was moderate lecuomatous, (b) 2 , severe lecuomatous (b) 3. If the cornea perforated, this was denoted as (b) $3 p$. Finally, if no vascularisation was present, it would be (c) 0 , if mild (c) 1 , if moderate (c) 2 , if severe, (c) 3 . Therefore a moderate keratitis involving $50 \%$ of the cornea, with mild opacity, and some vascularisation would be scored as (a) 2 (b) 1 (c) 1 . The most severe stage would be (a) 3 (b) 3p (c) 3 . In assessing overall severity the points were added together, so that a maximum of $9 p$ was obtainable (Table 1).

A masked randomised trial was initiated. The rabbits were treated as follows. One infected eye received anti-LPS, and where possible (infections established in both eyes) the contralateral eye served as a control, receiving saline. Anti-LPS or saline was administered as a lavage at the rate of 40 drops/minute for 5 minutes 3 times a day. The treated and control eyes were chosen at random. Treatment started as soon as the infection was clearly established, that is, after two days. The final appearance of the eyes was evaluated after eight days, by which time, anti-LPS had neutralised the effect of the pseudomonas.

Since we wished to determine merely whether the serum could control and limit the infection, the final result would not necessarily be a reversal of the lesions but a quiet eye with scar formation. In five severe cases topical corticosteroid drops (dexamethasone disodium phosphate) were added to this regimen after eight days, as it has been reported that steroids can cause a recurrence of the infection. ${ }^{17}{ }^{18}$ Steroids were also administered to five control eyes.

\section{Results}

In group A rabbits an infection developed in 22 out of 32 eyes inoculated. It developed in two days or less and varied in severity. In group B a severe infection developed in 10/10 eyes inoculated.

Table 2 shows the results of treatment with anti-

Table 2 Treatment of pseudomonas infected eyes

\begin{tabular}{lllll}
\hline Treatment & $\begin{array}{l}\text { No. of } \\
\text { eyes } \\
\text { treated }\end{array}$ & $\begin{array}{l}\text { Improved } \\
(\%)\end{array}$ & $\begin{array}{l}\text { Unchanged } \\
(\%)\end{array}$ & $\begin{array}{l}\text { Deteriorated } \\
(\%)\end{array}$ \\
\hline $\begin{array}{l}\text { Saline } \\
\text { Anti-LPS }\end{array}$ & 17 & $4(23 \cdot 5)$ & $4(23 \cdot 5)$ & $9(52 \cdot 9)$ \\
\hline${ }^{*} \chi^{2}=12 \cdot 76$, & $\mathrm{p}<0 \cdot 001$. & $13(86 \cdot 7)^{*}$ & $1(6 \cdot 7)^{* *}$ & $1(6 \cdot 7)^{* * *}$ \\
$\mathrm{p}<0 \cdot 001$. & & $\chi^{2}=1 \cdot 72$, & $\mathrm{p}<0 \cdot 1$, ND. & ${ }^{* * *} \chi^{2}=7 \cdot 94$, \\
\end{tabular}


Table 3 Morbidity index of corneas*

\begin{tabular}{|c|c|c|c|c|}
\hline \multicolumn{3}{|c|}{ Controls (normal saline) } & \multicolumn{2}{|l|}{ Treated } \\
\hline \multirow[t]{2}{*}{$\begin{array}{l}\text { Rabbit } \\
\text { No. }\end{array}$} & $\begin{array}{l}\text { Days post } \\
\text { treatment }\end{array}$ & Results $\dagger$ & $\begin{array}{l}\text { Days post } \\
\text { treatment }\end{array}$ & Results \\
\hline & 4 & & 4 & \\
\hline
\end{tabular}

\begin{tabular}{lllllllll}
\hline Group $A$ & & & & & & & \\
1 & 9 & 8 & 9 & 0 & 9 & 9 & 7 & + \\
2 & 9 & 9 & 9 & 0 & 9 & 9 & 7 & + \\
3 & 9 & 9 & $9 p$ & - & 4 & 6 & 6 & - \\
4 & 5 & 2 & 2 & + & 5 & 4 & 4 & + \\
5 & 3 & 2 & 2 & + & 9 & 6 & 4 & + \\
6 & 9 & 9 & 9 & 0 & 4 & 2 & 2 & + \\
7 & 6 & 8 & 9 & - & 9 & 8 & 6 & + \\
8 & 6 & 8 & 9 & - & 5 & 4 & 3 & + \\
9 & 6 & 8 & 9 & - & 6 & 6 & 4 & + \\
10 & 6 & 4 & 3 & + & & & & \\
11 & 6 & 8 & 9 & - & & & & \\
12 & 3 & 2 & 2 & + & & & & \\
Group $B$ & & & & & & & & + \\
13 & 8 & 9 & $9 p$ & - & 8 & 7 & 6 & + \\
14 & 8 & 9 & $9 p$ & - & 8 & 8 & 6 & + \\
15 & 8 & 9 & $9 p$ & - & 8 & 8 & 6 & + \\
16 & 8 & 9 & $9 p$ & - & 8 & 7 & 6 & + \\
17 & 8 & 8 & 8 & 0 & 9 & 9 & 9 & 0
\end{tabular}

*Summation of scores 0-3 of (a) area of keratitis, (b) depth of lesion, and (c) vascularisation. $p$ Indicates perforation of cornea. $\dagger=$ Improvement; $0=$ no change; $-=$ deterioration.

LPS compared with saline controls. Fifteen infected eyes were treated with anti-LPS, and $13(86.7 \%$, $\left.\chi^{2}=12.76, p<0.001\right)$ improved, with arrest of the keratitis and some with partial healing. Of the 17 saline treated infected eyes $4(23.5 \%)$ improved, 9 deteriorated, and 4 remained unchanged. The unchanged eyes were already in the most severe group, so further deterioration could only have led to perforation.

Table 3 shows the changes that occurred on the 1st, 4th, and 8th days. Five out of the 17 saline treated control eyes in groups A and B perforated by day 8 , $4 / 17$ improved spontaneously, 4 remained unchanged. Among anti-LPS treated eyes only 1 deteriorated, and 1 was unchanged. 8.

Table 4 shows the complete scores on day 1 and day

Fig. 1A shows the eye of rabbit 7 before treatment, and Fig. 1B shows the same eye after eight days of anti-LPS treatment. Five serum-treated eyes that received topical corticosteroid after the 8th day showed dramatic improvement, and three of the control eyes continued to deteriorate. These are not indicated in the tables.

\section{Discussion}

Our experimental model was similar to previous models used to assess the different modes of treatment for pseudomonas keratitis..$^{1314}$ Where possible the anti-LPS treated eye was compared with the contralateral eye of the same animal treated with saline. The eyes were allocated for treatment in a randomised

Table 4 Clinical evaluation of pseudomonas keratitis before and after treatment

\begin{tabular}{|c|c|c|c|c|c|c|c|c|c|c|c|c|}
\hline & \multicolumn{6}{|l|}{ Control } & \multicolumn{6}{|c|}{ Treated eye } \\
\hline & \multicolumn{3}{|l|}{ Ist day } & \multicolumn{3}{|l|}{ 8th day } & \multicolumn{3}{|l|}{ Ist day } & \multicolumn{3}{|l|}{ 8th day } \\
\hline & $\begin{array}{l}\text { Surface } \\
\text { (a) }\end{array}$ & $\begin{array}{l}\text { Depth } \\
\text { (b) }\end{array}$ & $\begin{array}{l}\text { Vessels } \\
\text { (c) }\end{array}$ & $\begin{array}{l}\text { Surface } \\
\text { (a) }\end{array}$ & $\begin{array}{l}\text { Depth } \\
\text { (b) }\end{array}$ & $\begin{array}{l}\text { Vessels } \\
\text { (c) }\end{array}$ & $\begin{array}{l}\text { Surface } \\
\text { (a) }\end{array}$ & $\begin{array}{l}\text { Depth } \\
\text { (b) }\end{array}$ & $\begin{array}{l}\text { Vessels } \\
\text { (c) }\end{array}$ & $\begin{array}{l}\text { Surface } \\
\text { (a) }\end{array}$ & $\begin{array}{l}\text { Depth } \\
\text { (b) }\end{array}$ & $\begin{array}{l}\text { Vessels } \\
\text { (c) }\end{array}$ \\
\hline \multicolumn{13}{|c|}{ Group $A$} \\
\hline 1 & 3 & 3 & 3 & 3 & 3 & 3 & 3 & 3 & 3 & 2 & 3 & 2 \\
\hline 2 & 3 & 3 & 3 & 3 & 3 & 3 & 3 & 3 & 3 & 2 & 2 & 3 \\
\hline 3 & 3 & 3 & 3 & 3 & $3 p$ & 3 & 1 & 2 & 1 & 2 & 2 & $2 \dagger$ \\
\hline 4 & 2 & 2 & 1 & 1 & 1 & $0^{*}$ & 2 & 2 & 1 & 1 & 2 & 1 \\
\hline 5 & 1 & 1 & 1 & 1 & 1 & $0^{*}$ & 3 & 3 & 3 & 1 & 2 & 1 \\
\hline 6 & 3 & 3 & 3 & 3 & 3 & 3 & 1 & 2 & 1 & 1 & 1 & 0 \\
\hline 7 & 2 & 2 & 2 & 3 & 3 & 3 & 3 & 3 & 3 & 2 & 3 & 1 \\
\hline 8 & 2 & 2 & 2 & 3 & 3 & 3 & 2 & 2 & 1 & 1 & 1 & 1 \\
\hline 9 & 2 & 2 & 2 & 3 & 3 & 3 & 2 & 2 & 2 & 2 & 1 & 1 \\
\hline 10 & 2 & 2 & 2 & 1 & 1 & $1^{*}$ & 1 & 2 & 1 & 1 & 1 & 0 \\
\hline 11 & 2 & 2 & 2 & 3 & 3 & 3 & & & & & & \\
\hline 12 & 1 & 1 & 1 & 1 & 1 & $1^{*}$ & & & & & & \\
\hline \multicolumn{13}{|c|}{ Group B } \\
\hline 13 & 3 & 2 & 3 & 3 & $3 p$ & 3 & 3 & 2 & 3 & 2 & 2 & 2 \\
\hline 14 & 3 & 2 & 3 & 3 & $3 p$ & 3 & 3 & 2 & 3 & 2 & 2 & 2 \\
\hline 15 & 3 & 2 & 3 & 3 & $3 p$ & 3 & 3 & 2 & 3 & 2 & 2 & 2 \\
\hline 16 & 3 & 2 & 3 & 3 & $3 p$ & 3 & 3 & 2 & 3 & 2 & 2 & 2 \\
\hline 17 & 2 & 3 & 3 & 3 & 2 & 3 & 3 & 3 & 3 & 3 & 3 & $3 \dagger$ \\
\hline
\end{tabular}

* Indicates controlled eyes that improved. †Indicates treated eyes that deteriorated or did not improve. $3 \mathrm{p}$ Indicates perforation. 


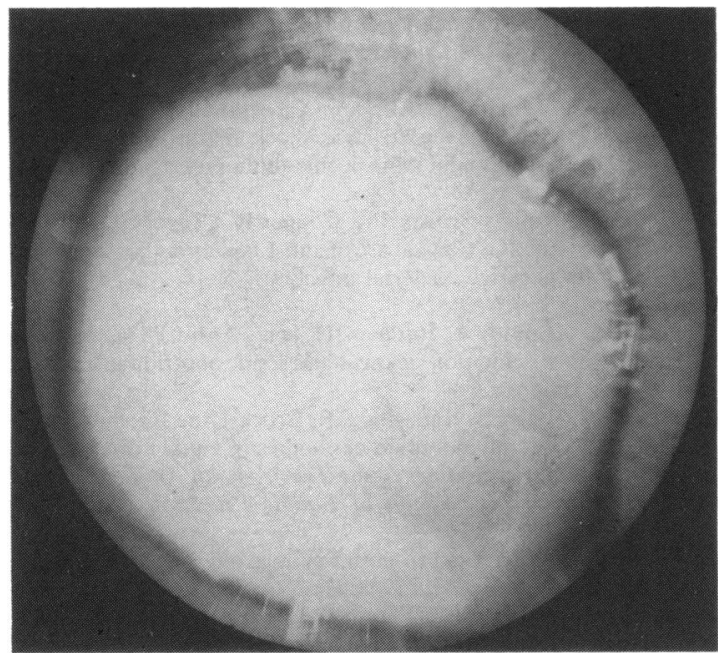

Fig. 1A Rabbit eye infected with Pseudomonas aeruginosa. Note extensive opacification and infection.

fashion. In addition assessment was conducted by outside observers to eliminate bias.

Anti-LPS treatment resulted in significant improvement in the infected eyes. IgG present in the anti-LPS binds to LPS located on the outer cell membrane of pseudomonas. This activates complement and causes the lysis and destruction of bacteria. This specific IgG also binds to the LPS released from the killed bacteria, in part neutralising it. Moreover, such binding enhances host phagocytosis of the 'free' LPS. Treatment in this experimental series was initiated only when the infection was firmly established. In

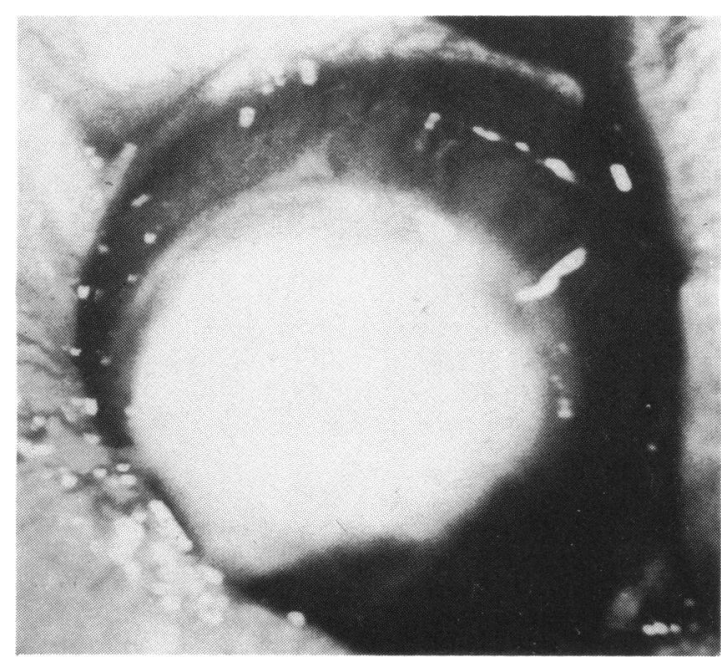

Fig. 1B Same eye after eight days of anti-LPS therapy. The extent of keratitis and scarring is much reduced with control of infection.
10/15 eyes the plasma was used on eyes severely infected-that is with morbidity indices of six or more -and the eyes responded after 3-4 days. The improvement in the corneal infection involved all three parameters measured, area of keratitis, depth of lesion, and degree of vascularisation.

In milder cases the plasma was effective with reversal of the lesion, whereas in severe cases the plasma effectively brought the infection under control, and the final result was a firm scar (Table 3). It would be advantageous to initiate therapy at the earliest sign of clinical infection, but in this experimental analysis we wished to determine the plasma's efficacy against established infections.

The purely physical action (lavage) of instillation of solutions on the corneal surface has been shown to be beneficial by removing necrotic tissue and the exoenzymes produced by pseudomonas. ${ }^{14}$ Therefore saline was administered in the same manner to the control eyes. It would thus seem that the dual action of anti-LPS (bactericidal and antitoxic) is effective in pseudomonas keratitis. Significantly, no eyes in the anti-LPS treated group perforated. Bohigan et al. ${ }^{19}$ have shown that, in contrast to the 'melting' character of pseudomonas keratitis in man, the condition in rabbits follows an ulcerative, necrotic course, such that the addition of collagenase inhibitors to the normal regimen had no significant effect on the clinical course.

We believe that the addition of anti-LPS could significantly change the corneal stromal reaction. In another study, with carbenicillin and gentamicin, it was found that the keratitis continued to worsen for up to seven days before improvement was noted..$^{16}$ In a different experimental model anti-LPS has already been observed to be more effective therapeutically than gentamicin. In our study with anti-LPS, improvement commenced within three days. Experiments in progress show that anti-LPS is also effective in similar infections in guinea-pigs.

The dosage regimen used was arbitrary ( 40 drops/ min for 5 minutes 3 times daily for 8 days). We have yet to determine whether this may be modified or simplified. Treatment by the subconjunctival route will also be investigated, as preliminary results indicate that this method is tolerated by the normal rabbit eye.

A possible complication of anti-LPS treatment could be a systemic reaction to foreign equine antigens. However, this has not occurred in other experimental models where anti-LPS has been used, or in veterinary clinical practice. 112

The addition of topical corticosteroid after eight days resulted in an additional dramatic decrease in superficial vascularisation and a reduction in the area of scarring. The serum treatment does not therefore 
contraindicate subsequent use of steroids, and indeed this seems to be beneficial.

We believe that the use of anti-LPS in the treatment of pseudomonas keratitis in rabbits shows favourable results, with none of the disadvantages of conventional antibiotic therapy, and that it has a potential application in the therapy, and perhaps prophylaxis, of the condition in man.

This work was supported by grants from the Anglo-American Corporation and the South African Medical Research Council.

\section{References}

1 Norrby R. Current status of pseudomonas infections and antibiotics. Scand J Infect Dis 1981; suppl 9: 81-6.

2 Smith LR, Lipsley JJ, Laskin OL, et al. Double blind comparison of the nephrotoxicity and auditory toxicity of gentamicin and tobramycin. N Engl J Med 1980; 302: 1106-9.

3 Bergan T. Pathogenic factors of Pseuedomonas aeruginosa. Scand J Infect Dis 1981; suppl 29: 7-12.

4 Howes EL, Aronson SB, McKay DG. Ocular vascular permeability. Effect of systemic administration of bacterial endotoxin. Arch Ophthalmol 1970; 84: 360-7.

5 Germuth FG Jr, Maumenee AE, Senterfit LB, Pollack AD. Immunohistologic studies on antigen-antibody reactions in the avascular cornea. I. reactions in rabbits actively sensitised to foreign protein. J Exp Med 1962; 115: 919-28.

6 Belmont JB, Ostler HB, Dawson CR, Schwab I, Dulay D. Noninfectious ring-shaped keratitis associated with Pseudomonas aeruginosa. Am J Ophthalmol 1982; 93: 338-41.

7 Mondino BJ, Rabin BS, Kessler E, Gallo J, Brown SI. Corneal rings with Gram-negative bacteria. Arch Ophthalmol 1977; 95: $2222-5$.
8 Fisher MW. Development of immunotherapy for infections due to Pseudomonas aeruginosa. J Infect Dis 1974; suppl 130: S149-51.

9 Gaffin SL, Grinberg Z, Abraham C, Birkham J, Schechter G. Protection against haemorrhagic shock in the cat by human plasma containing endotoxin-specific antibodies. J Surg Res 1981; 31: 18-21.

10 Gaffin SL, Robins-Brown RM, Cooper R. Gregory M, Badsha $\mathrm{N}$, Brock-Utne JG. Clinical use of anti-LPS antibodies in animals with Gram-negative bacterial infections. S Afr J Sci 1982; 78: 91-2.

11 Gaffin SL, Zanotti A, Jordaan JH, et al. Anti-LPS successfully treated shock, radiation sickness and septic abortion in animals. $S A f r J S c i$ in press.

12 Gaffin SL, Baker B, Katzwinkel R, Brock-Utne JG, du Preez J. Clinical use of antiendotoxin antibodies in equine diseases. In: Milne FJ, ed. Proceedings of the Twentyeighth Annual Convention, American Association of Equine Practitioners. Golden, 1983: 335-40.

13 Furgiuele F. Treatment of pseudomonas infection of the rabbit cornea. Am J Ophthalmol 1968; 66: 276-9.

14 Hessburg PC, Truant JP, Penn WP. Treatment of pseudomonas keratitis in rabbits. Am J Ophthalmol 1966; 61: 49-54.

15 Wiggins RL. Experimental studies on the eye with polymyxin B. Am J Ophthalmol 1952; 35: 83-99.

16 Bohigian G, Okumoto M, Vanenton M. Experimental pseudomonas keratitis. Arch Ophthalmol 1971; 86: 432-7.

17 Harbin T. Recurrence of a corneal pseudomonas infection after topical steroid therapy. Report of a case. Am J Ophthalmol 1964; 58: $670-4$.

18 Burns R. Pseudomonas aeruginosa keratitis. Mixed infections of the eye. Am J Ophthalmol 1969; 67: 257-62.

19 Bohigian C, Valenton M, Okumoto M, Caraway W. Collagenase inhibitors in pseudomonas keratitis. Arch Ophthalmol 1974.; 91: $52-6$. 